\title{
Optimal sizing and location of multiple distributed generation for power loss minimization using genetic algorithm
}

\author{
Abdulhamid Musa ${ }^{1}$, Tengku Juhana Tengku Hashim² \\ ${ }^{1}$ Department of Electrical and Electronic Engineering, Petroleum Training Institute (PTI), Effurun, Nigeria \\ ${ }^{2}$ Department of Electrical Power Engineering, Universiti Tenaga Nasional (UNITEN), Kajang, Malaysia
}

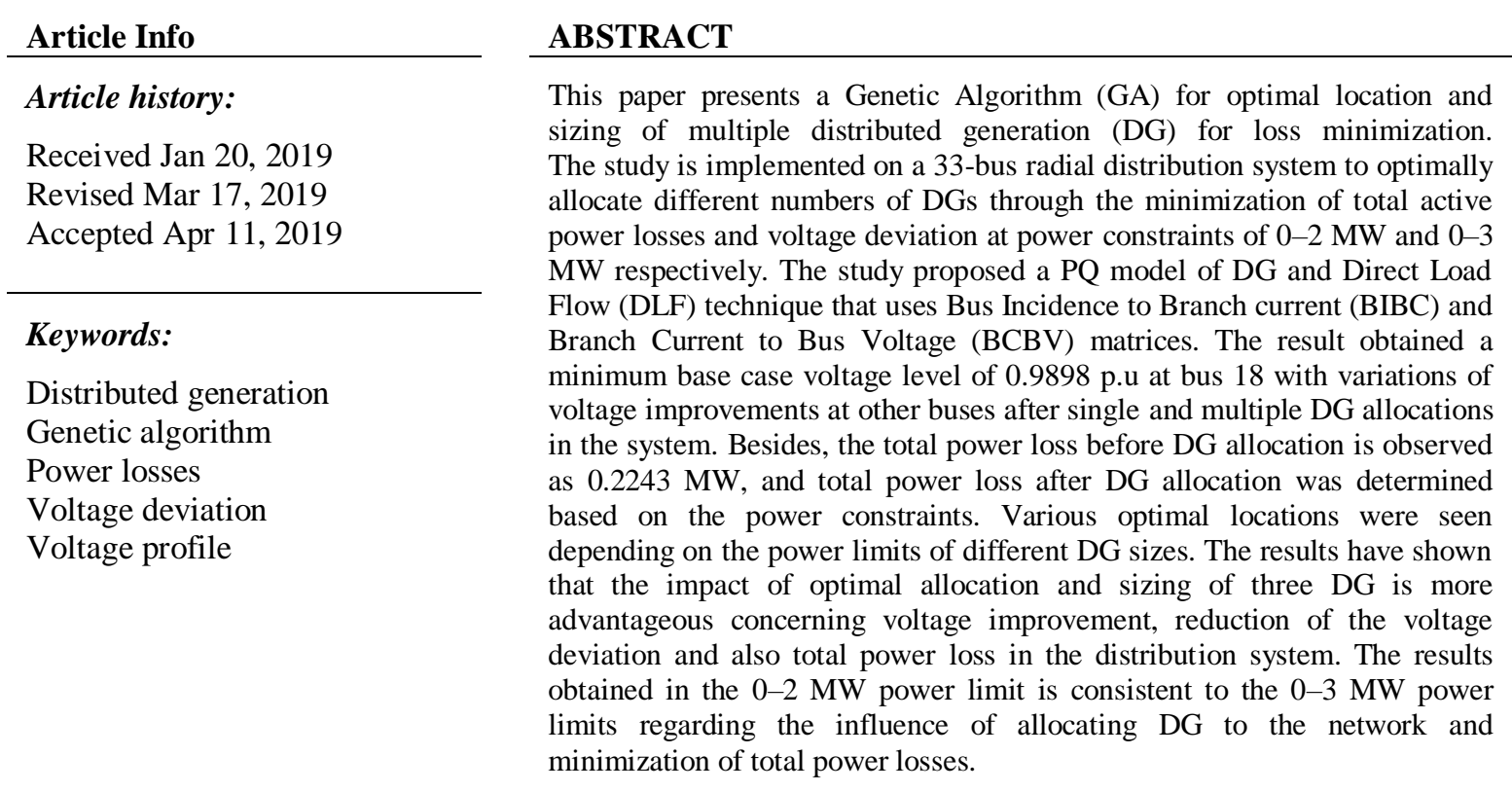

Copyright $\odot 2019$ Institute of Advanced Engineering and Science. All rights reserved.

\section{Corresponding Author:}

Tengku Juhana Tengku Hashim,

Department of Electrical Power Engineering,

Universiti Tenaga Nasional (Putrajaya Campus),

KM-7 Jalan IKRAM-UNITEN, 43000, Kajang, Selangor, Malaysia.

Email: juhana@uniten.edu.my

\section{INTRODUCTION}

Energy is one of the fundamental areas for the existence and development of humankind and is a crucial issue in technical and socioeconomic operations of power systems. However, the significance of electricity as an energy source is a function of its advancement in technology in all societies that generate a considerably high demand for electric power. Therefore, the need for electric energy is never ending due to an increase in energy demand as a result of rapid population and economic growth, industrialization, and power quality and reliability [1]. Accordingly, electric utilities are becoming more stressed as the distribution systems are operating based on their constraints with the growing load. A significant problem which impact the efficiency and security of the power distribution networks is the loss of power occurring within the process of energy delivering to the consumers. The losses can either be technical or non-technical. Significant power losses during the transmission as well as distribution processes was also found to be as a result of reduced efficiency of the existing systems. Research has revealed that distributed power losses as a result of the Joule effect is responsible for an approximated proportion of $13 \%$ of the total energy that is generated [2]. Nonetheless, a proportion estimated to be $70 \%$ of the total losses have been associated with the 
primary as well as the secondary distribution systems. Conversely the remaining proportion of $30 \%$ is believed to be as a result of inefficient transmission and sub-transmission lines. On the other hand, distribution losses are approximated to be $15.5 \%$ of the generation capacity, a proportion that is slightly lower than the target level of $7.5 \%$. Previous research work has indicated that a consumption of between $10 \%$ and $13 \%$ of the total generated power is classified as loss at the distribution system (real power loss). Therefore, it is beneficial to consider placing the DG in the distribution system to lower the loss of power while improving the bus voltages [3]. The attempts and desire to minimize losses in the distribution, however, has led to significant focus in the last decade, globally. Lowering the loss in a distribution network has been considered a critical requirement for enhancing the reliability and efficiency of power systems. Many researchers have carried out research concerning the impact that distributed generation (DG) has on a distributed system. DG concepts that aims at loss minimization have been presented in [4]. DG planning and optimization have been implemented and reviewed by [5], cost of DG and cost of tariff [6], and issues and challenges of integration of DG are discussed in [7]. Moreover, reduction of loss can lower the power flows on distribution feeders, hence yielding positive impacts on the capacity release, voltage profiles and voltage stability of the system. Considering utilities, it can be argued that DG units that are located near the loads have significantly lower the losses of energy in the distribution systems. Nonetheless, penetration of DG units at high levels can introduce numerous challenges to distribution systems such as voltage rise, power fluctuations, low voltage stability, and high losses because of reverse power flow [8]. DG placement and sizing has been identified as one of the major problems due to the combination of possible buses, number of DGs and their capacities. However, the maximum benefit of integrating DG to a distributed system is a function of determining the suitable location and sizing of a DG. By installing DG at a suitable position and sizing it appropriately, the losses can be minimized. The idea of implementing DG for loss reduction needs special attention because of various benefits that as a result of objectives of DG implementation. This is why many studies by researchers have been performed on this issue and can be by no means exhaustive. Several algorithms have been proposed to place DG in a distributed system that includes an analytical method and soft computing approach. Analytical method is proposed in research by [9] to identify the optimal size and location of single and multiple DGs. Other knowledge contributions include a combination of analytical and computing technique with the aim of achieving comparison in power loss minimization and relative efficiency on the model. The comparison between the analytical and fuzzy method in [10] have proposed a methodology that comprises of two-stage approach to achieve optimal sizing as well as placement of DGs.

For finding optimal sizing and location of DG, there are quite a number of algorithms which have been employed. In this work, the optimization method selected is Genetic Algorithm whereby the technique is selected to find the optimal sizing and locations of one, two and three DGs. GA is famous among evolutionary computation (EC) algorithms, as it has been applied widely to offer solutions to problems related to optimization. The strategy was produced by John Holland in the year 1975 through the span of the 1970s and lastly promoted by one of his understudies, David Goldberg, who presented a guide offering a solution to the difficult problem that involved the control of gas-pipeline transmission during his dissertation project writing. The algorithm presents a stochastic search technique inspired by the concepts of genetics and natural selection. This algorithm belongs to the larger class of evolutionary algorithm (EA) that utilizes techniques inspired by natural evolution to produce solutions to the optimization problems and does not cover different generation of the DG [11]. It is population-based that evolve under various selection guidelines to maximize or minimize "fitness" [12]. GA has a good global search capacity with a moderately quick convergence rate. GA optimization has been implemented by various researchers to optimally allocate and size a DG with various objective functions. In [13], GA is investigated to find the most appropriate location of Static Var Compensator (SVC) and sizing of SVC to enhance the voltage profile using GA. The study also, determined voltage saddle-node points on IEEE 30-bus system using SVC for an increase in load demand and loss of generation where MATLAB program with MATPOWER was used. Voltage saddlenode points are calculated for $10 \%$, and $20 \%$ increase in load demands, loss of generation at bus 13 only, and loss of generation at bus 13 and bus 27 respectively. Besides, GA was used for solving the problem of optimization with the aim of minimizing loss of active power by placing DG strategically and implemented on 33-bus radial distribution system [14]. According to that research, the reduction of computational efforts needed to select an appropriate location was investigated and the approach was able to decide on the loss sensitivity to inject active power at different nodes. Besides, the use of a GA as a way of optimizing size and locating the distributed generation units in a distribution system in [15]. The GA was implemented through a MATLAB package and automatic interaction with the load flow program to obtain the optimum solutions. In this study, the fitness function, the deviation of cumulative voltage, active and reactive losses of power, was selected to get the best result. The work as described in [16], was focused at solving for the optimal location and capacity of distributed generation with the help of GA while making considerations of the vulnerable node edification in an active distribution network. The proposed method was believed to offer 
solutions to multi-objective problems and implemented on IEEE 30-bus, which presented both economic and technical advantages, and also offer robust concerns to the selected objectives. Moreover, in [17], the study investigated the optimal allocation of renewable-based DG resources in rural areas with the help of GA. The study adopted a power flow model on the basis of the availability of data and the performance with respect to power losses investigated at varying scenarios. Optimization of location and size of DG were found on the process of minimizing loss. Also, the fuel saving, reduction of loss as well as other benefits to the environment relating to the proposed DG size at the optimum location were quantified. Three potential benefits that were gained after installing renewable-based DG were also quantified.

This paper presents optimal sizing and location of multiple distributed generation for power loss minimization using genetic algorithm. It is aim at establishing a method that will find the optimal location and sizing of DGs in radial distribution networks with real power loss minimization and improving on voltage profile of the distributed network using Genetic Algorithm. The objective function (OF) of the proposed method is to improve the voltage and minimize the total power loss of the system. The optimization codes were implemented in MATLAB 2016a in order to evaluate the objective functions of improving voltage profile and minimizing total power losses in IEEE 33-bus distribution system.

\section{METHODOLOGY}

This section describes the methods of DG modelling, formulation of the optimization problem, fitness function, load flow and implementation of the optimization algorithm for solving optimal problems.

\subsection{DG Modelling}

Accurate load representation is a necessary task for power system planning, analysis and control and it is well recognised in the power system industry [18]. There are two approaches to modelling DG units in power system studies, namely connection type and DG type [19]. However, PQ model was applied by many researchers including [20] and is adopted for this study because it is found to be effective for the distribution system load flow in terms of safety and economic run of a grid, reduction of energy consumption, the guarantee of normal working of industry and scientific experiments. Using (1), the active powers of the load at any bus $i$ of DG are updated.

$$
\mathrm{P}_{\mathrm{i}}=\mathrm{P}_{\text {load,i }}-\mathrm{P}_{\mathrm{DG}, \mathrm{i}}
$$

Where,

$\mathrm{P}_{\mathrm{i}}$-the modified active powers at bus $\mathrm{i}$ after addition of DG.

$\mathrm{P}_{\text {load,i }}$-the initial active powers at bus $\mathrm{i}$.

$\mathrm{P}_{\mathrm{DG}, \mathrm{i}}$-the real power of the $\mathrm{DG}$ represented as negative loads in bus $i$.

\subsection{Formulation of the Optimization Problem}

The optimization problem formulation considers minimizing voltage drop and total power loss of the network. The search for optimal solution is subject to the following objective functions and technical constraints. The objective function (OF) for this study is calculated using (2).

$$
\mathrm{OF}=\mathrm{w}_{1} \mathrm{f}_{1}+\mathrm{w}_{2} \mathrm{f}_{2}
$$

Where $f_{1}$ and $f_{2}$ are functions of fitness functions and given as in (3) and (4). Similarly, $w_{1}=0.5$ and

$w_{2}=0.5$ are weighing factors in which $w_{1}$ is weight as applied to total real power loss minimization, and $w_{2}$ is weight given to voltage deviation minimization. The weights are indicated to provide equal importance to each impact indices and depend on the required analysis [21].

$$
\mathrm{f}_{1}=\frac{\sum_{\mathrm{i}=1}^{\mathrm{L}}\left(\mathrm{P}_{1}(\mathrm{i})\right)_{\mathrm{DG}}}{\sum_{\mathrm{i}=1}^{\mathrm{L}}\left(\mathrm{P}_{1}(\mathrm{i})\right)_{\text {BASE }}}
$$

Where,

$\mathrm{P}_{\mathrm{l}}(\mathrm{i})_{\mathrm{DG}}$-power loss with DG at bus $i$

$\mathrm{P}_{\mathrm{l}}(\mathrm{i})_{\mathrm{BASE}}-$ power loss without DG at bus $i$.

$$
\mathrm{f}_{2}=\text { Voltage Deviation (VD) }=\sum_{\mathrm{i}}^{\mathrm{n}}\left|\mathrm{V}_{\mathrm{i}}-\mathrm{V}_{\mathrm{i}, \mathrm{ref}}\right|
$$


Here, $\mathrm{V}_{\mathrm{i}}^{\mathrm{ref}}$ is taken as 1.0 pu indicating the reference voltage, $\mathrm{V}_{\mathrm{i}}$ is the real voltage at bus $i$ and $n$ is the total number of buses in the network.

\subsection{Fitness Function}

The adopted fitness function presented a method of measuring the solutions quality after the generation by the GA. The function determined how the candidate solution and the actual solution differed. Using (5), the fitness function can be calculated. The design of the function was a significant part of the entire optimization method for the modeling process.

$$
\mathrm{f}(\mathrm{x}, \mathrm{u})=0.5 \times \frac{\sum_{\mathrm{i}=1}^{\mathrm{L}}\left(\mathrm{P}_{1}(\mathrm{i})\right)_{\mathrm{DG}}}{\sum_{\mathrm{i}=1}^{\mathrm{L}}\left(\mathrm{P}_{1}(\mathrm{i})\right)_{\mathrm{BASE}}}+0.5 \times \sum_{\mathrm{i}}^{\mathrm{n}}\left|\mathrm{V}_{\mathrm{i}}-\mathrm{V}_{\mathrm{i}, \mathrm{ref}}\right|
$$

Where $x$ denotes the variables to be determined and $u$ represents all the dependent variables.

The constraints for the optimal DG placement formulation are DG location constraints, real power constraints, and voltage drop constraints and are calculated using (6), (7) and (8) respectively.

$$
\text { Bus No. } 2 \leq \text { DG location } \leq \text { nth bus }
$$

Where $n$ indicates the total number of buses.

DG size will be less than or equal to the total load power according to the literature [22]. Therefore,

$$
\begin{aligned}
& \mathrm{P}_{\mathrm{DG}}^{\min } \leq \mathrm{P}_{\mathrm{DG}} \leq \mathrm{P}_{\mathrm{DG}}^{\max } \\
& V_{\min } \leq\left|V_{i}\right| \leq V_{\max }
\end{aligned}
$$

Where $\mathrm{P}_{\mathrm{DG}}^{\min }$ and $\mathrm{P}_{\mathrm{DG}}^{\max }$ indicate minimum and maximum DG power limits. Also, $V_{\min }$ and $V_{\max }$ indicate minimum and maximum voltage limits.

\subsection{Load Flow Analysis for Radial Distribution System and Implementation of Genetic Algorithm}

Various methods including conventional and direct load flow (DLF) are available for the analysis of balanced and unbalanced distribution system. Besides, conventional load flow techniques such as NewtonRaphson Method, Gauss Siedel method may become inefficient for load flow studies due to convergence issues [23] and consequently unable to give accurate result values of line flows and line voltages in the distribution system [24]. However, DLF technique that uses BIBC (Bus Incidence to Branch current) and BCBV (Branch Current to Bus Voltage) matrices is a robust and efficient way for distribution systems analysis and it is utilized for this study. The IEEE 33-bus test feeder shown in Figure 1 is used for this study. The test feeder in the Figure is connected to $12.66 \mathrm{kV}$ and has one feeder with four different laterals, 32 branches and a total peak load of $3715 \mathrm{~kW}$ and $2300 \mathrm{kVAr}$. The total loss of the base case system is $211.20 \mathrm{~kW}$. The implementation of GA for the optimal placement and sizing of DG with system total active power loss minimization is chosen algorithmically, as outlined in [25]. However, the parameters used in the proposed GA design and their values are population size of 100 , crossover probability of 0.85 and mutation probability 0.03 at maximum iteration of 100 .

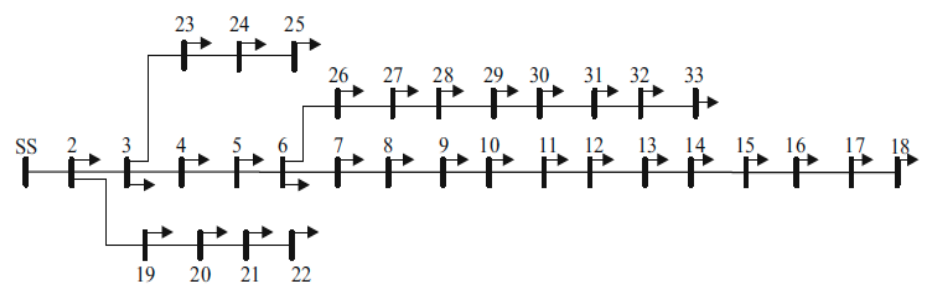

Figure 1. Single line diagram of the 33-bus test distribution system

\section{RESULTS AND DISCUSSION}

The developed algorithm is used for testing the proposed study in finding the optimal DG location and sizing for the IEEE 33-bus distribution network. To run a GA program, load flow program was run on the system to get the base case voltage at each bus and the total real power loss of the network. This section

Optimal sizing and location of multiple distributed generation for power loss... (Abdulhamid Musa) 
will provide the simulation result and analysis of 1 DG, 2 DGs and 3 DGs' locations for loss minimization to a 33-bus distribution network with power constraints of 0-2 MW and 0-3 MW. This is according to the literature that the DG size should be less than the total load power of the lines [22], which is 3.715 MW. Therefore, the duo of the power limits at one, two and three optimal allocations of DGs are chosen since are chosen for this study to verify the capability and robustness of the proposed study.

\subsection{Convergence Characteristics of Running the GA}

The convergence characteristics of the objective function for 100 iterations with constant crossover and mutation probabilities for 1 DG, 2 DGs and 3 DGs at $0-2 \mathrm{MW}$ and 0-3 MW are shown in Figure 2a and $2 b$. Objective function (OF) is minimized when the DG is at the optimum bus location and size at set up termination point, which is 100 iterations. Primarily, the drop in the value of the OF curve is sharp and gradually decreases to a constant value as the number of iterations increases.

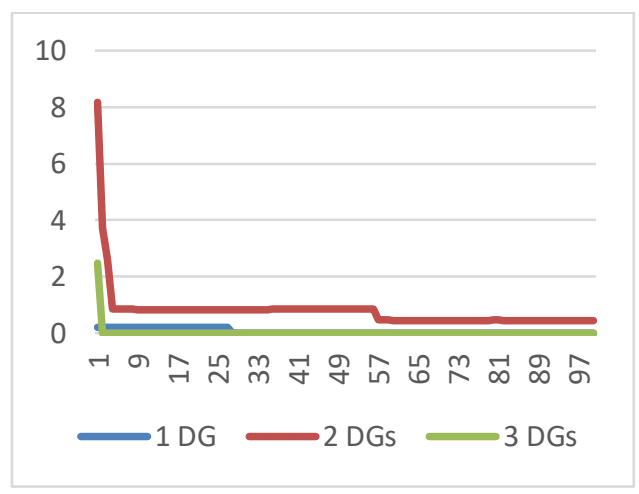

(a)

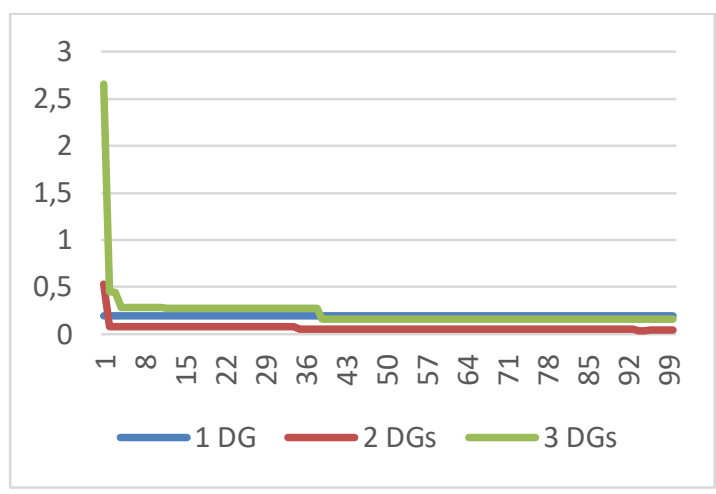

(b)

Figure 2. Convergence characteristics for optimum sizing and location of DG for IEEE 33-bus distribution system (a) 0-2 MW power limit (b) 0-3 MW power rating

\subsection{Effect of Single and Multiple DG Allocations on Voltage with 0-3 MW Power Constraints}

The bus voltages of the 33-bus networks before and after the allocation of DG into the system were simulated in MATLAB where minimum bus voltage at base case and optimal location and sizing of DGs are observed as 0.9898 pu at bus 18; 0.9974 pu at bus 7; 0.9973 pu at bus 29 and 0.9973 pu at bus 6 respectively. The voltage profile orientation for the three combinations of optimal DG allocation and sizing for $0-3 \mathrm{MW}$ power constraints is shown in Figures 3. From the figure, the total voltage deviation (VD) of the IEEE 33-bus at the base case $\left(V D_{\text {base }}\right)$ obtained is $0.2012 \mathrm{~V}$. On the other hand, the total voltage deviation obtained with one, two, and 3 optimal locations and sizing of DGs $\left(V D_{D G}\right)$, which are calculated using equation (4) are $0.00466 \mathrm{pu}, 0.0314 \mathrm{pu}$ and $0.0317 \mathrm{pu}$ respectively. However, the percentage of voltage performance VP calculated using equation 9 for $0-3 \mathrm{MW}$ are $76.83 \%, 84.39 \%$ and $84.24 \%$ respectively. Various voltage profiles are obtained as a result of different optimal allocations of DG sizes and locations that increase in the current flowing through the radial distribution system.

$$
\% \mathrm{VP}=\frac{V D_{\text {base }}-V D_{D G}}{V D_{\text {base }}} \times 100
$$

\subsection{Optimal Allocation of the DG and Total Power Loss Minimization for 0-2 MW and 0-3 MW Power Constraints}

The optimization results for the power constraints at single and multiple DGs are presented in Tables 1 and 2. It can be seen from the tables that various optimal locations are obtained for different numbers of DG allocated in the distribution system, which is a typical characteristics of population-based metaheuristic algorithms. However, it is observed that the total power loss of the IEEE 33-bus distribution system without DG integration is $0.2243 \mathrm{MW}$. Meanwhile, the tables present the optimal locations and sizing of DG, and total power loss without and with DG, which indicate a significant power loss reduction when DG is connected. 


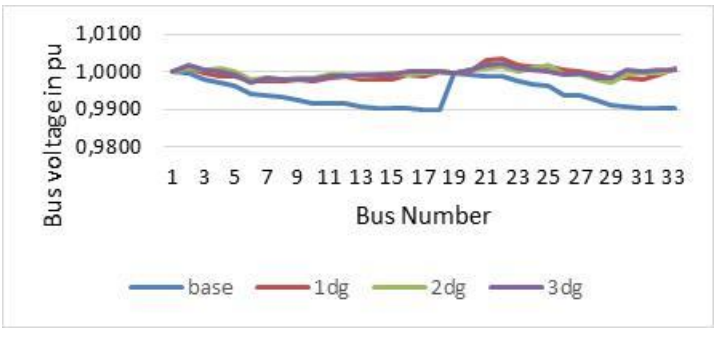

Figure 3. Voltage profiles for IEEE 33-bus distribution system without and with 3 DGs at 0-3 MW constraints

Table 1. The Optimization Results for 0-2 MW for Single and Multiple DG Allocations

\begin{tabular}{|c|c|c|c|c|c|}
\hline $\begin{array}{l}\text { No. of } \\
\text { DG }\end{array}$ & $\begin{array}{c}\text { DG } \\
\text { location }\end{array}$ & $\begin{array}{l}\text { DG size } \\
\text { (MW) }\end{array}$ & $\begin{array}{c}\text { Total Power loss without DG } \\
\text { (MW) }\end{array}$ & $\begin{array}{c}\text { Total Power loss with DG } \\
\text { (MW) }\end{array}$ & $\begin{array}{l}\% \text { Power loss } \\
\text { reduction }\end{array}$ \\
\hline 1 & Bus 9 & 0.5305 & 0.2243 & 0.0456 & 79.67 \\
\hline 2 & $\begin{array}{l}\text { Bus } 18 \\
\text { Bus } 10 \\
\text { Bus } 10\end{array}$ & $\begin{array}{l}0.4912 \\
1.0000 \\
0.3914\end{array}$ & 0.2243 & 0.2032 & 9.41 \\
\hline 3 & $\begin{array}{c}\text { Bus } 9 \\
\text { Bus } 14\end{array}$ & $\begin{array}{l}0.0262 \\
0.0276\end{array}$ & 0.2243 & 0.1885 & 15.96 \\
\hline
\end{tabular}

Table 2. The Optimization Results for 0-3 MW for Single and Multiple DG Allocations

\begin{tabular}{|c|c|c|c|c|c|}
\hline $\begin{array}{l}\text { No. of } \\
\text { DG }\end{array}$ & $\begin{array}{c}\text { DG } \\
\text { location }\end{array}$ & $\begin{array}{l}\text { DG size } \\
\text { (MW) }\end{array}$ & $\begin{array}{c}\text { Total Power loss without DG } \\
\text { (MW) }\end{array}$ & $\begin{array}{l}\text { Total Power loss with DG } \\
\text { (MW) }\end{array}$ & $\begin{array}{l}\% \text { Power loss } \\
\text { reduction }\end{array}$ \\
\hline 1 & Bus 15 & 2.1410 & 0.2243 & 0.07051 & 68.56 \\
\hline 2 & $\begin{array}{l}\text { Bus } 33 \\
\text { Bus } 2\end{array}$ & $\begin{array}{l}0.3959 \\
1.1255\end{array}$ & 0.2243 & 0.0189 & 91.57 \\
\hline 3 & $\begin{array}{c}\text { Bus } 17 \\
\text { Bus } 20 \\
\text { Bus } 2\end{array}$ & $\begin{array}{c}0.41882 \\
0.8959 \\
0.9918\end{array}$ & 0.2243 & 0.0647 & 71.15 \\
\hline
\end{tabular}

One of the main objectives of this study is to minimize the power losses in the distribution system. The implementation of the GA based optimization for the $0-2 \mathrm{MW}$ and $0-3 \mathrm{MW}$ constraints shown in Tables 1 and 2 explained the total performance of the system concerning minimizing total power of power losses. From Table 1, the percentage of power loss for $0-2$ MW limits are $79.67 \%, 9.41 \%$ and $15.96 \%$ for one, two and three DGs integrations at optimal locations and sizing. However, the results of power losses minimization for the $0-3 \mathrm{MW}$ limits have are obtained to be $68.56 \%, 91.57 \%$ and $71.15 \%$ that corresponds to one, two and three DGs at optimal locations and sizing. The percentage of power losses reduction can be calculated using equation (10) where $P_{\text {loss,without } D G}$ and $P_{\text {loss,with } D G}$ indicates the total power loss without and with DG, respectively.

$$
\% \text { power losses reduction }=\frac{P_{\text {loss,without } D G}-P_{\text {loss }, \text { with } D G}}{P_{\text {loss,without } D G}} \times 100 \%
$$

\section{CONCLUSION}

This paper presents optimal sizing and location of multiple distributed generation for power loss minimization using genetic algorithm. However, PQ model is adopted for this study because it is found to be effective for the distribution system load flow in terms of safety and economic run of a grid among other factors. Also, direct load flow technique that uses Bus Incidence to Branch current and Branch Current to Bus Voltage matrices is utilized for this study. The optimization result has demonstrated that different power constraints provide variation of DG sizes and locations, level of voltage support and total power loss of the distribution system. It also shown that the impact of optimal sizing and location of DG is substantial concerning voltage improvement, reduction of the voltage deviation and total power loss in the distribution system. Likewise, higher voltage performance is indicated when two distributed generations are optimally allocated for both 0-2 MW and 0-3 MW power generations where voltage deviations were determined minimum for each generation. Besides, more power loss is minimized considering allocation of a distributed generation at 0-2 MW and allocation of two distributed generations at 0-3 MW respectively. 


\section{ACKNOWLEDGEMENTS}

The authors would like to express their gratitude to Universiti Tenaga Nasional (UNITEN) for providing the funding for this research and acknowledges the UNITEN Internal Grant (UNIIG) Project Code J510050699.

\section{REFERENCES}

[1] A. Hasibuan, S. Masri, and W. A. F. W. B. Othman, "Effect of distributed generation installation on power loss using genetic algorithm method," IOP Conference Series: Materials Science and Engineering, vol. 308, no. $012034,2018$.

[2] U. Sultana, A. B. Khairuddin, M. M. Aman, A. S. Mokhtar, and N. Zareen, "A review of optimum DG placement based on minimization of power losses and voltage stability enhancement of distribution system," Renewable and Sustainable Energy Reviews, vol. 63, pp. 363-378, 2016.

[3] S. M. Hossain and A. H. Chowdhury, "Multi-objective optimal placement of distributed generations for dynamic loads," International Journal of Electrical and Computer Engineering (IJECE), vol. 9, no. 4, pp. 2303-2313, 2019.

[4] B. Banhthasit, C. Jamroen, and S. Dechanupaprittha, "Optimal Generation Scheduling of Power System for Maximum Renewable Energy Harvesting and Power Losses Minimization," International Journal of Electrical and Computer Engineering (IJECE), vol. 8, no. 4, pp. 1954-1966, 2018.

[5] B. Singh and J. Sharma, "A review on distributed generation planning," Renewable and Sustainable Energy Reviews, vol. 76, pp. 529-544, 2017.

[6] J. P. Sridhar and R. Prakash, "Multi-objective whale optimization based minimization of loss, maximization of voltage stability considering cost of DG for optimal sizing and placement of DG," International Journal of Electrical and Computer Engineering (IJECE), vol. 9, no. 2, pp. 835-839, 2019.

[7] A. A. J. Jeman, N. M. S. Hannoon, N. Hidayat, M. M. H. Adam, I. Musirin, and V. V, "Small signal fault analysis for renewable energy (wind) power system distributed generation by using MATLAB software (simulink)," Indonesian Journal of Electrical Engineering and Computer Science, vol. 13, no. 3, pp. 1337-1344, 2019.

[8] N. Mithulananthan, D. Q. Hung, and K. Y. Lee, Intelligent Network Integration of Distributed Renewable Generation, Green Energy and Technology. DOI 10.1007/978-3-319-49271-1 (Green Energy and Technology). 2017.

[9] S. N. G. Naik, D. K. Khatod, and M. P. Sharma, "Analytical approach for optimal siting and sizing of distributed generation in radial distribution networks," IET Generation, Transmission \& Distribution, vol. 9, no. 3, pp. 209-220, 2013.

[10] M. Manas, B. J. Saikia, and D. C. Baruah, "Optimal Distributed Generator Sizing and Placement by Analytical Method and Fuzzy Expert System: a Case Study in Tezpur University, India," Technology and Economics of Smart Grids and Sustainable Energy, vol. 3, no. 1, 2018.

[11] P. Laxmi, J. Umale, and S. Mahajan, "MoHPBGA: Multi-objective Hierarchical Population Balanced Genetic Algorithm using MapReduce," International Journal of Computer Applications, vol. 40, no. $2,2012$.

[12] P. Rustem, "Genetic Algorithms: An Overview with Applications in Evolvable Hardware, Bio-Inspired Computational Algorithms and Their Applications, Dr. Shangce Gao (Ed.), ISBN: 978-953-51-0214-4, InTech, Available from: http://www.intechopen.com/books/bio-inspired-computational-algorithms-and-theirapplications/genetic-algorithms-an-overview " 2012.

[13] B. V. Srikanth and A. L. Devi, "Optimal location and sizing of SVC using genetic algorithm to find voltage saddle node points for improving voltage stability," International Journal of Pure and Applied Mathematics, vol. 114, no. 12 , pp. 477-489, 2017.

[14] A. A. Saleh, A.-A. A. Mohamed, A. M. Hemeida, and A. A. Ibrahim, "Comparison of Different Optimization Techniques for Optimal Allocation of Multiple Distribution Generation," 2018 International Conference on Innovative Trends in Computer Engineering (ITCE 2018), Aswan University, Egypt., vol. 2018 International Conference on Innovative Trends in Computer Engineering (ITCE 2018), Aswan University, Egypt., 2018.

[15] M.F.Kotb, K.M.Shebl, M. E. Khazendar, and A. E. Husseiny, "Genetic Algorithm for Optimum Siting and Sizing of Distributed Generation," Proceedings of the 14th International Middle East Power Systems Conference (MEPCON'10), Cairo University, Egypt., pp. 433-440, 2010.

[16] T. P. Nguyen, T. T. Tran, and D. N. Vo, "Improved stochastic fractal search algorithm with chaos for optimal determination of location, size, and quantity of distributed generators in distribution systems," Neural Computing and Applications, 2018.

[17] M. H. Albadi, A. S. Al-Hinai, N. N. Al-Abri, Y. H. Al-Busafi, and R. S. Al-Sadairi, "Optimal Allocation of Renewable-based DG Resources in Rural Areas Using Genetic Algorithms," 2012 Asia-Pacific Power and Energy Engineering Conference (APPEEC), Shanghai, China 2012.

[18] A. Arif, Z. Wang, J. Wang, B. Mather, H. Bashualdo, and D. Zhao, "Load Modeling - A Review," IEEE Transactions on Smart Grid, 1-1. , 2017.

[19] E. N. Azadani, C. Canizares, and K. Bhattacharya, "Modeling and Stability Analysis of Distributed Generation," 2012 IEEE Power and Energy Society General Meeting, pp. 1-8, 2012.

[20] V. Kumar, S. Swapnil, R. Ranjan, and V. R. Singh, "Improved Algorithm for Load Flow Analysis of Radial Distribution System," Indian Journal of Science and Technology, vol. 10, no. 18, 2017. 
[21] C. Yammani, S. Maheswarapu, and S. Matam, "Optimal Placement of Multi DGs in Distribution System with Considering the DG Bus Available Limits," Energy and Power Engineering, vol. 2, no. 1, pp. 18-23, 2012.

[22] M. Shekeew, M. Elshahed, and M. Elmarsafawy, "Impact of optimal location, size and number of distributed generation units on the performance of radial distribution systems," in 2016 IEEE 16th International Conference on Environment and Electrical Engineering (EEEIC), 2016, pp. 1-6.

[23] S. S. Parihar and N. Malik, "Power flow analysis of balanced radial distribution system with composite load model," presented at the 2017 Recent Developments in Control, Automation \& Power Engineering (RDCAPE), Noida, India, 2017.

[24] F. Iqbal, M. T. Khan, and A. S. Siddiqui, "Optimal placement of DG and DSTATCOM for loss reduction and voltage profile improvement," Alexandria Engineering Journal, 2017.

[25] D. Tiwari and S. R. Ghatak, "Performance enhancement of distribution system using optimal allocation of distributed generation \& DSTATCOM," presented at the 2017 International Conference on Innovative Mechanisms for Industry Applications (ICIMIA), Bangalore, India, 2017.

\section{BIOGRAPHIES OF AUTHORS}

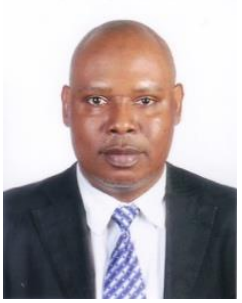

Abdulhamid Musa was born in Zaria, the Kaduna state of Nigeria in March 1971. He obtained Bachelor's degree in Electrical Engineering from Bayero University Kano (BUK), Nigeria in 1997 and is currently a Masters student of Electrical Engineering in Universiti Tenaga Nasional (UNITEN), Malaysia. His current research work is on artificial intelligence and optimization in electrical power system.

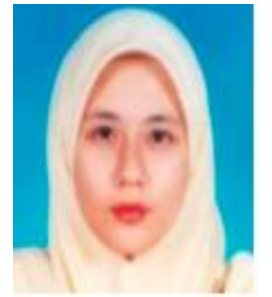

Tengku Juhana Tengku Hashim was born in Kuantan, Pahang, Malaysia in May 1979. She received her B. Eng. In Electrical Power Engineering in 2002 and master's in electrical engineering in 2004 from Universiti Tenaga Nasional (UNITEN), Selangor, Malaysia. She obtained her $\mathrm{PhD}$ in Electrical, Electronics and Systems Engineering from Universiti Kebangsaan Malaysia (UKM), Bangi Malaysia in 2014 specializing in the area of optimization of voltage control methods in an active distribution system. Her current research interest includes power quality and optimization in power system analysis. 